\title{
Questes
}

\section{Le Jardin de Rhétorique. L'arbre, le prince et l'écrivain à la fin du Moyen Âge}

\section{Estelle Doudet}

\section{(2) OpenEdition}

1 Journals

\section{Édition électronique}

URL : http://journals.openedition.org/questes/1749

DOI : 10.4000/questes. 1749

ISSN : 2109-9472

\section{Éditeur}

Les Amis de Questes

\section{Édition imprimée}

Date de publication : 15 mai 2003

Pagination : 6-8

ISSN : 2102-7188

\section{Référence électronique}

Estelle Doudet, « Le Jardin de Rhétorique. L'arbre, le prince et l'écrivain à la fin du Moyen Âge », Questes [En ligne], 4 | 2003, mis en ligne le 01 janvier 2014, consulté le 15 septembre 2020. URL : http:// journals.openedition.org/questes/1749

\section{(C) Association des amis de "Questes »}


$\mathrm{Si}$, au XIV ${ }^{\mathrm{e}}$ siècle, s'amorça un recul des cultures, cela ne s'accompagna pas de leur renouveau mais d'une avancée des friches et des landes. Désormais, les forêts qui ont survécu ne sont plus des domaines naturels intouchables mais des lieux dominés par l'homme. Dorénavant, maîtres des eaux et forêts, créés par Philippe le Bel, et verdiers les administreront.

\section{Le Jardin de Rhétorique \\ L'arbre, le prince et l'écrivain à la fin du Moyen Âge Estelle DOUDET}

Semeur de mots chez Chrétien de Troyes, glaneur sous la plume de Christine de Pisan, l'écrivain médiéval recherche une figuration métaphorique dans les travaux des champs, dans le contact avec Dame Nature. Le texte lyrique naît dans la reverdie du printemps, la réflexion stylistique s'organise en jardin de rhétorique. En son centre se trouve l'arbre, symbole de la connaissance, axe structurant du texte dont il est parfois la table des matières, telle la dame-arbre s'enracinant au frontispice du Breviari d'Amors de Matfre Ermengau. A la fin du Moyen Âge français, l'écrivain qui choisit une expression engagée, politique et moraliste, fait de l'arbre l'un des éléments essentiels de sa figuration : au prince-arbre répond un poète-jardinier, ordonnateur des fleurs de rhétorique dont se pare le Verger de France, ou élagueur des branches pourrissantes qui le menacent.

L'arbre, métaphore du pouvoir politique dans les textes littéraires, appartient à un fonds intertextuel particulièrement riche. Dès les premières attestations vernaculaires, il est l'image du roi en majesté. Il symbolise la pérennité glorieuse de la lignée. Charles V, chez Christine de Pizan, est comparé au «précieux cèdre du Liban ». La métaphore princière joue aux frontières de 
l'allégorie chez Jean Molinet, qui pleure sur l'Arbre de Bourgogne abattu après Nancy.

Les œuvres moralistes des $\mathrm{XIV}^{\mathrm{e}}$ et $\mathrm{XV}^{\mathrm{e}}$ siècles, à l'exemple du Songe $d u$ Vergier, donnent aussi au souverain le rôle d'un ordonnateur consciencieux de plantes, d'un «ortalin » aux soins judicieux. Le prince est un sage qui doit savoir établir la préséance des hommes vertueux sur les conseillers superflus, exerçant sa subtilité d'analyse entre le bon et le mauvais, ce qui mérite la louange et le blâme. Les Rhétoriqueurs comme George Chastelain développent particulièrement la métaphore du devoir horticole chez les gouvernants. Louis XI succédant à son père peut-il jeter ensemble les ronces inutiles et la vertu de la plante féconde?

«O excellent roy, et l'arbre doncques qui oncques ne fut sterile, et qui tant a rendu fruit et fleur noble, le veux-tu coupper en racine, le veux-tu submettre à la cognée pour fagoter, pour ruer au feu avec les inutiles, avec les ronces et espines portant grief? »(George Chastelain, Déprécation pour Pierre de Brézé, VII, 59-60).

Le prince jardinier est bien le frère de l'écrivain encomiaste, et celui-ci peut légitimement lui rappeler que le gouvernement de la France s'assimile à un jardin rhétorique.

Le trouble menace parfois l'arbre. Insidieusement s'insère le danger de la pourriture, qui attaque l'intérieur même de l'être. Prince et écrivain doivent alors choisir de se faire «essarteurs », élagueurs taillant sans pitié les arbustes, dans un jardin gagné par les ronces. Ils se munissent d'armes tranchantes, glaives du blâme moral ou de l'exclusion politique. Le verger devient champ de bataille.

De la forêt royale des princes à la « reverdie » du discours politique qui atteste de leur bonne renommée, se dessine donc un parcours idéal, l'arbre généalogique des rois de France devenant le centre du jardin de France, orné pour la postérité des fleurs de la littérature. 
Nul étonnement à ce que le lecteur soit invité à se promener lui-même en ce lieu, à lire à l'ombre des arbres comme le lui conseille Jean Robertet (Douze Dames de Rhétorique). Enserrant le livre de son attention toujours en mouvement, le récepteur se fait, non arbre, mais treille.

\author{
Par grant ardeur je m'essaye et traveille \\ d'en vous mouvoir vostre ententive oreille (...) \\ Par quoy s'en vous a veine qui someille \\ Je vous prie donc d'en susciter la treille \\ Et que le coeur s'expose et appareille \\ A enfonser ses mémoires labiles.
}

George Chastelain, Miroer des nobles hommes de France, VI, 206.

La «treille» de la lecture est une architecture interne de la mémoire, qui s'éveille à l'appel de la poésie. Elle enserre l'arbre-texte, le couvre de sa verdure et de ses fleurs pour que, par cette nouvelle richesse, il s'élance de nouveau vers la création.

\title{
«Le végétal en fête » \\ Retour sur la symbolique végétale dans la liturgie Andrea MARTIGNONI
}

Arbres, plantes et feuillages tiennent une place de première importance dans la liturgie et dans l'univers de la ritualité cérémonielle du Moyen Age. Leur puissance symbolique possède une fonctionnalité tout à fait performative dans le rituel. Arbre de vie et feuillage de printemps par exemple, sont au cœur de l'organisation et du déroulement des festivités pascales. Par le recours aux éléments végétaux dans l'actualisation de la scénographie cérémonielle précise et codifiée, le dimanche des Rameaux ou des Palmes réactualise et commémore l'entrée du Christ à Jérusalem. 